\title{
ACOUSTICS OF THE SINGING VOICE
}

$\mathrm{A}^{\mathrm{T}}$

$T$ the Friday Evening Discourse given in the Royal Institution, London, on June 18, Mr. G. Mackworth-Young spoke on "What Happens in Singing". Much argument has been devoted to the question of whether singing is an art or a science. To the extent that the singer needs as his prime requisites a nice appreciation of pitch and good muscular control, it is primarily an art; yet in the process of learning to sing it is helpful to know something of the physies and physiology of the voice, though, of course, one does not while singing continually and consciously set the vocal apparatus into positions which theory would indicate as desirable. It is rather like riding a bicycle; at the beginning it is necessary to know something of the technique of propelling and balancing the machine, but in time this becomes automatic and to think consciously of each movement soon results in falling off.

'The human vocal apparatus consists of the chest (bellows), larynx containing the vocal cords (source of vibration) and the throat, mouth and nasal cavities (resonators). The production of tone has often been likened to that in a reed pipe of the wood-wind class, but perhaps a brass instrument of the trombone type gives a closer analogy, since both the size of the resonators and the tension and length of the vibrating tissues are adjustable. The true or lower vocal cords are set in vibration by approximating their edges under the tension necessary to produce a note of the required frequency, and the breath is expelled through the narrow slit between them. This process sets the edges in vibration either as a whole (normal register) or in part (falsetto register), and these vibrations may be seen with a combination of the laryngoscope and stroboscope. The mathematical theory of this vibrating system has been given by Wegel. Experiments on excised larynxes have shown that, as would be expected, the quality of the unaided vocal cords is raucous and unmusical. It is mainly by the modulating influence of the resonating cavities upon the laryngeal tone that man is able to transcend the lower animals in speech and song, though the parrot and certain members of the ape family possess this faculty to a limited extent.

We turn to the important modifications produced on this still rather unmelodious 'buzzer' note by the resonance column, which it now has to pass through. The natural vibrations of the latter in the absence of a buzzer note may be heard in whispered speech or in whistling, when the vocal bands are drawn aside and a stream of air passes through practically uninterrupted at the larynx. Phoneticians usually distinguish three principal resonances: the back cavity (throat), the front cavity (of the mouth) and the nasal cavity. The acoustic impedance of the latter is then a 'shunt' upon the front part of the mouth. Further, the nasal cavity may be completely cut out, in the production of certain sounds, by the large impedance of the constriction where it joins the throat. In the absence of damping, each cavity may be regarded as an acoustic capacitanee and each constriction as an inertance.

Of course, the division into capacitances and inertances must not be regarded as too rigorous. In some vowels the whole resonance system approximates to a wide open funnel stretching from larynx to lips. Actually, the damping is very large, much more so than in a wind instrument, owing to the resilient nature of the walls of the cavities. This has the practical effect of broadening all the resonances. It makes it rather difficult, in fact, to test the natural resonances of the system held in a given position by such methods as bringing tuning forks in front of the mouth. Again, although tables of resonances for various vowels are given, there are small discrepancies between the resonances detected by different investigators, and those not entirely due to phonetic uncer. tainties - for example, in the pronunciation of the vowels or the pitch of the cord note. Damping tends, in fact, to confound together the theories of Helmholtz and Hermann on the subject of the wave forms of vowels.

While it is true that we find, with the latter, that as one sings a vowel up the scale each cord-note has the 'formant' of the fixed resonance cavities impressed upon it, these resonances are so broad that the probability will be that a number of the harmonics of the cord-note will elicit some resonance in the mouth cavities, giving apparent agreement with the Helmholtz relative pitch theory of vowel overtones. This has the result that, within limits, the wave-form of a vowel is preserved as the cord-note is changed. This would not be so in a brass instrument where rigid walls and consequent sharp resonances impress a very pronounced formant on each note, altering the wave form as the player moves up the scale.

One difference between artificial wind instruments and the voice is in the type of resonance employed. In nearly all wind instruments standing waves are set up in the resonance tube, and the pitch of the note is therefore decided by the tube length. The voice, on the other hand, employs resonators of the Helmholtz type in which the inertance of the mouth and nose orifices is in series with the capacitance of the oral cavities. The resonance frequency therefore depends not only on the size of the cavities but also on the size and shape of the opening. The throat and mouth cavities are chambers of easily variable shape having soft elastic walls. They form resonators of low ' $Q$ ' in comparison to the resonator of a wind instrument, and so are readily tuned to a range of pitch. They accept a note from the vocal cords and give it body and quality by tuning their resonances to coincide with either the fundamental cord frequency or with certain harmonics. The auxiliary head resonators, being of fixed size and shape, contribute higher harmonics by forced vibration.

The fact that the bass voice can produce notes of wave-length 11-14 ft. indicates that here the voice resonance must all take place on the higher harmonics. Although the greater part of the sound energy is distributed among these harmonic resonances, we normally associate the pitch with the fundamental. This is due to the ear, which has the gift of extracting the fundamental, even if weak, from such harmonics as are presented to it.

Before dealing with the resonance compass of the various voices, it is necessary to consider briefly the question of vowel production. The combination of two resonances at a particular frequency produces an additional quality in the voice which no other 
instrument possesses and which the ear perceives as a vowel. Different vowels are produced by modulating the resonance of the cavities in much the same way as when reinforcing a vocal cord note. However, the vowel resonances ('formants') need not bear harmonic relation to each other. It follows that, in singing, the cavities are required to produce resonances which must be harmonics of the vocal note and at the same time fall within the formants of the vowel. These two requirements may conflict, and the claims of the note must then take precedence. This is the case in the upper range of the soprano voice where vowel production becomes a matter of great difficulty. The lower voices, being richer in harmonics within the resonant compass, are less troubled by this effect.

Much research has been carried out to determine the range of resonance in the throat and mouth cavities employed in the various voices, and recently this work has been greatly facilitated by the introduction of new electro-acoustic techniques. The normal range of resonance of the throat cavity for the male voice extends from $A_{1} b$ to $E_{2} b$ in the treble clef. Bass and baritone notes from the lowest up to $E_{1}$ b (on the bottom line of the treble clef) are reinforced on whatever harmonics lie within this compass. Notes lying between $E_{1} b$ and $G_{1}$ are resonated on the fundamental by a forced enlargement of the throat cavity. In women the normal compass of resonance stands squarely in the middle of the soprano voice extending upwards from the $G_{1}$ in the treble clef to the $F_{2} \#$ above. The notes within this range will naturally be reinforced on the fundamental, while lower tones find resonance on the first or second harmonic. When the voice rises above $F_{2} \#$ the throat resonance must be raised above its normal range, and this is achieved in trained voices by an enlargement of the throat cavity aperture.

Mr. Mackworth-Young has himself demonstrated the existence of two resonant zones in the throat having a compass of four semi-tones each in the men's voices (four and eight semi-tones in women's voices). It was found that if the vocal note happened to have harmonics in both zones, then both harmonics were heard. Notes which have two harmonics within the same zone may be resonated on either one but not both. The exact significance of this discovery awaits interpretation.

The normal compass of resonance for each voice shows a remarkable uniformity among singers of differing ages and nationality, individual variations rarely amounting to more than a semi-tone in either direction. The vowel, demanding as it does absolute pitch of resonance, is even more exacting in its requirements. This uniformity is achieved because the note of a Helmholtz resonator varies according to its size in relation to its opening; and as the mouth and throat capacities of the two sexes and various ages differ, so the mouth openings differ with them, thus maintaining the same proportions.

The throat cavity resonance on any particular note appears to be independent of the vowel which is being sung. It would appear, therefore, that throat resonance plays little or no part in vowel production, but the matter is still open to question. The nature of the vowel sounds has been under investigation since the beginning of the nineteenth century, and the pitches of the formants involved in the production of each vowel are now well established. For some vowels the lower formant does lie within the compass of throat resonance, while the upper formant is undoubtedly supplied by mouth resonance. For other vowels (for example, ai and ee) the mouth is divided by the tongue into two cavities which appear to provide the two formants independently of the throat resonance.

Much remains to be done to elucidate the acoustical processes in full of orchestral wind instruments; so it is with the voice. A good singer may be readily distinguishable from an indifferent on $\theta$ merely by listening to him; but if the indifferent singer is to be helped to improve, the scientific principles underlying the good singer's skill must. be studied. In particular, studies should be made. of 'attack' and 'vibrato' as practised by trained singers.

\section{THE INTERNATIONAL BOTANICAL CONGRESS IN PARIS}

IN 1854 the Société Botanique de France was 1 founded, and it was very fitting that the centenary of this event should coincide with the meeting of the Eighth International Botanical Congress in Paris during July 2-14. The Congress was very well attended; the incomplete list of members and those accompanying members contains more than two thousand names, derived from about seventy different countries. Thus this Congress was even more truly international than that held in Stockholm in 1950.

The work of the Congress was divided between twenty-seven sections : International Union of Botanical Sciences; Nomenclature; Terminology; Taxonomy; Palæobotany; Palynology ; Phytogeography; Morphology and Anatomy; Cytology; Genetics; Plant Physiology ; Agronomy ; Forestry; Standardization of Raw Materials of Plant Origin; Ethnobotany; Bryology ; Phycology ; Lichenology; Mycology ; Plant Pathology ; Bacteriology ; Protection of Materials and Equipment; Soil and Water Mierobiology ; Nature Conservation; History of Botany; Botanic Gardens; Mediterranean Botany.

The above list may seem to disperse the subject over a very wide field, but it should also be noted that many sections were still further divided; for example, there were three sub-sections of Physiology, namely, Nutrition, Growth, Physiological Ecology. On a day chosen at random there were thirty-five different papers being read simultaneously; thus the subject had been so dissected that there were very few papers of general interest, and those attending the Congress had to be very ruthless in their decisions which section to attend, otherwise much valuable time was lost trying to keep track of two fields of interest housed in widely separate parts of the Sorbonne. One wonders if this process of sub-division has gone too far and there really is no longer a science called 'botany' but only some twenty or thirty separate sciences. One factor, however, eased this situation. The nine volumes comprising the Congress papers were available at the beginning and enabled one to decide which communications were most appropriate to one's own interest.

Most sections, while allowing time for miscellaneous communications, concentrated on a few main topics on which colloquia were held. These colloquia took the form of a rapport which usually summarized the position and lasted for an hour, followed by 